Response to Stain et al., (2017)

\title{
The ultra-high risk phase: a missed opportunity for physical health care
}

\author{
Rebekah Carney $^{\mathrm{a}}$, Tim Bradshaw ${ }^{\mathrm{b}}$, \& Alison R. Yung ${ }^{\mathrm{a}, \mathrm{c}}$
}

\author{
Author affiliations: \\ ${ }^{a}$ Division of Psychology and Mental Health, University of Manchester, M13 9PL, UK \\ ${ }^{\mathrm{b}}$ Division of Nursing, Midwifery and Social Work, University of Manchester, M13 9PL, UK \\ ${ }^{c}$ Greater Manchester Mental Health NHS Foundation Trust, M25 3BL, UK
}

*Corresponding author:

Rebekah Carney

Division of Psychology and Mental Health, University of Manchester, Room 3.306, Jean McFarlane Building, Oxford Road, Manchester, M13 9PL, UK

Tel: +44 (0)161 3067914

Email: rebekah.carney@postgrad.manchester.ac.uk

\section{Funding Declaration}

This work was supported by the Economic and Social Research Council [ES/J500094/1].

This is the author manuscript accepted for publication and has undergone full peer review but has not been through the copyediting, typesetting, pagination and proofreading process, which may lead to differences between this version and the Version of Record. Please cite this article as doi: $10.1111 /$ eip.12493

This article is protected by copyright. All rights reserved. 
We read with interest the paper by Stain et al., (2017) published online for 'Early Intervention in Psychiatry'. The paper provides important findings and carries implications for future service development. Despite evidence for the importance of early intervention, the authors found that current service provision in England falls substantially below standard for young people at ultra-high risk for psychosis (UHR).

According to the National Institute for Health and Care Excellence (NICE, 2013), in the UK the primary recommended treatment for this group are psychological therapies such as Cognitive Behavioural Therapy (CBT) and family therapies, both of which were offered in only half of services surveyed (Stain et al., 2017). Due to the serious metabolic side-effects of antipsychotic medication, pharmacological interventions are not recommended as a firstline treatment for this group. Yet, one of the most striking findings arising from this paper is that $50 \%$ of services for UHR individuals surveyed offered antipsychotic medication. Given the sudden and sustained metabolic side-effects associated with antipsychotic medication, this is an area which should be explored further.

Since this review has been conducted, the new NHS national waiting standards have been published which state that early intervention and detection services should provide NICE concordant care for UHR individuals as well as those with first-episode psychosis, (NHS England, 2016). The new guidelines recommend routine physical health monitoring for FEP. However, this is not extended to the UHR group as it is assumed that they are not prescribed antipsychotic medication and that they are not at increased risk for poor physical health. This is despite recent findings that show that UHR individuals display numerous risk factors for poor physical health, including increased smoking rates, high rates of physical inactivity, increased levels of substance use and poor diet (Carney et al., 2016). Additionally, our recent qualitative study with UHR individuals, parents and clinicians found this group experienced multiple barriers to living a healthy lifestyle including psychiatric symptoms, reduced opportunity for healthy behaviours and inadequate social support (Carney et al.., 2017).

We have previously argued that UHR individuals should have their physical heath monitored and that interventions to promote healthy living should be developed for this group. We note the UHR phase represents a unique opportunity to intervene to prevent future ill- 
health (Carney et al., 2015; 2017). The review by Stain et al., (2017), showing that a high number of UHR services utilize antipsychotic medication strengthens our argument that there is a failed opportunity to prevent serious physical health problems in an already vulnerable group.

We agree with Stain et al.'s recommendation that there should be a focus on staff training and allocation of resources to enable NICE guidelines to be followed within services. The reasons for prescription of antipsychotics should be explored further. Additionally, given the rates of antipsychotic medication, together with the often unhealthy lifestyles of UHR individuals, staff should be trained in the importance of looking after physical health, including how lifestyle can affect both mental and physical health and the metabolic side effects associated with antipsychotic use. It is possible that UHR individuals are offered physical health interventions elsewhere, for example from their GP. However, this does not detract from the need to investigate and address physical health in this group. We also emphasise that there should be a more integrated approach to overall care; incorporating both mental and physical health monitoring.

\section{References}

Carney, R., Cotter, J., Bradshaw, T., \& Yung, A.R. (2017). Examining the physical health and lifestyle of young people at ultra-high risk for psychosis: A qualitative study involving service users, parents and clinicians. Psychiatry Research, 255, 87-93.

Carney, R., Cotter, J., Bradshaw, T., Firth, J., \& Yung, A.R. (2016). Cardiometabolic risk factors in young people at ultra-high risk for psychosis: A systematic review and meta-analysis. Schizophrenia Research, 170, 290-330.

Carney, R., Bradshaw, T., \& Yung, A.R. (2015). Monitoring of physical health in services for young people at ultra-high risk of psychosis. Early Intervention in Psychiatry. Early view: https://doi.org/10.1111/eip.12288.

NHS England. (2016). Implementing the early intervention in psychosis access and waiting time standard:

Guidance. https://www.england.nhs.uk/mentalhealth/wpcontent/uploads/sites/29/2016/04/eip-guidance.pdf. [Accessed 20/06/2017].

NICE (2013). Psychosis and schizophrenia in adults: Prevention and management. NICE Clinical Guideline (CG178). London, United Kingdom. 
Response to Stain et al., (2017)

Stain, H.J., Mawn, L., Common, S., Pilton, M., \& Thompson, A. (2017). Research and practice for ultra-high risk for psychosis: A national survey of early intervention in psychosis services in England. Early Intervention in Psychiatry. Early view: https://doi.org/10.1111/eip.12443.

This article is protected by copyright. All rights reserved. 


\section{University Library}

\section{- M M I E R R V A gateway to Melbourne's research publications}

Minerva Access is the Institutional Repository of The University of Melbourne

Author/s:

Carney, R;Bradshaw, T;Yung, AR

Title:

Ultra-high risk phase: A missed opportunity for physical health care

Date:

2018-04-01

Citation:

Carney, R., Bradshaw, T. \& Yung, A. R. (2018). Ultra-high risk phase: A missed opportunity for physical health care. EARLY INTERVENTION IN PSYCHIATRY, 12 (2), pp.267-268. https:// doi.org/10.1111/eip.12493.

Persistent Link:

http://hdl.handle.net/11343/293889 